\title{
The Second Manchester Birth Defects Conference, 1 to 3 October 1986
}

One disadvantage of joining the 'establishment' is the increasing frequency of invitations to give lectures and take part in symposia. This might not seem an onerous task, particularly for someone once accused of being prepared to talk to a tethered mule'. The catch comes when the organisers request a written manuscript for subsequent publication in the 'proceedings'. The absence of such a request made my visit to Manchester to take part in the Second Birth Defects Conference an unadulterated pleasure; unadulterated, that is, I ntil the second day when the deputy editor of the Journal asked me to prepare a manuscript describing the whole meeting!

As in 1984, the meeting was held at the Holly Royde Conference Centre. Just over 100) participants (see below) gathered for the three days. including the majority of Britain`s clinical geneticists and an impressive number of foreign visitors. Taking a lesson from the Italians whose nets capture birds as they migrate to the sun. Dr Donnai used a combination of reputation, charm, and guile to interrupt the homeward flight from the Berlin Congress of several foreign notables.

The meeting was sufficiently varied to be stimulating but small enough to be friendly and presented at a pace which allowed everyone to learn.

The variety of the intellectual diet showed the study of birth defects need not be a narrow remit. Professor John Edwards examined the genetic consequences of the Chernobyl incident with his usual depth and perception. About 70000 local inhabitants were exposed to more than 10 rem, which is

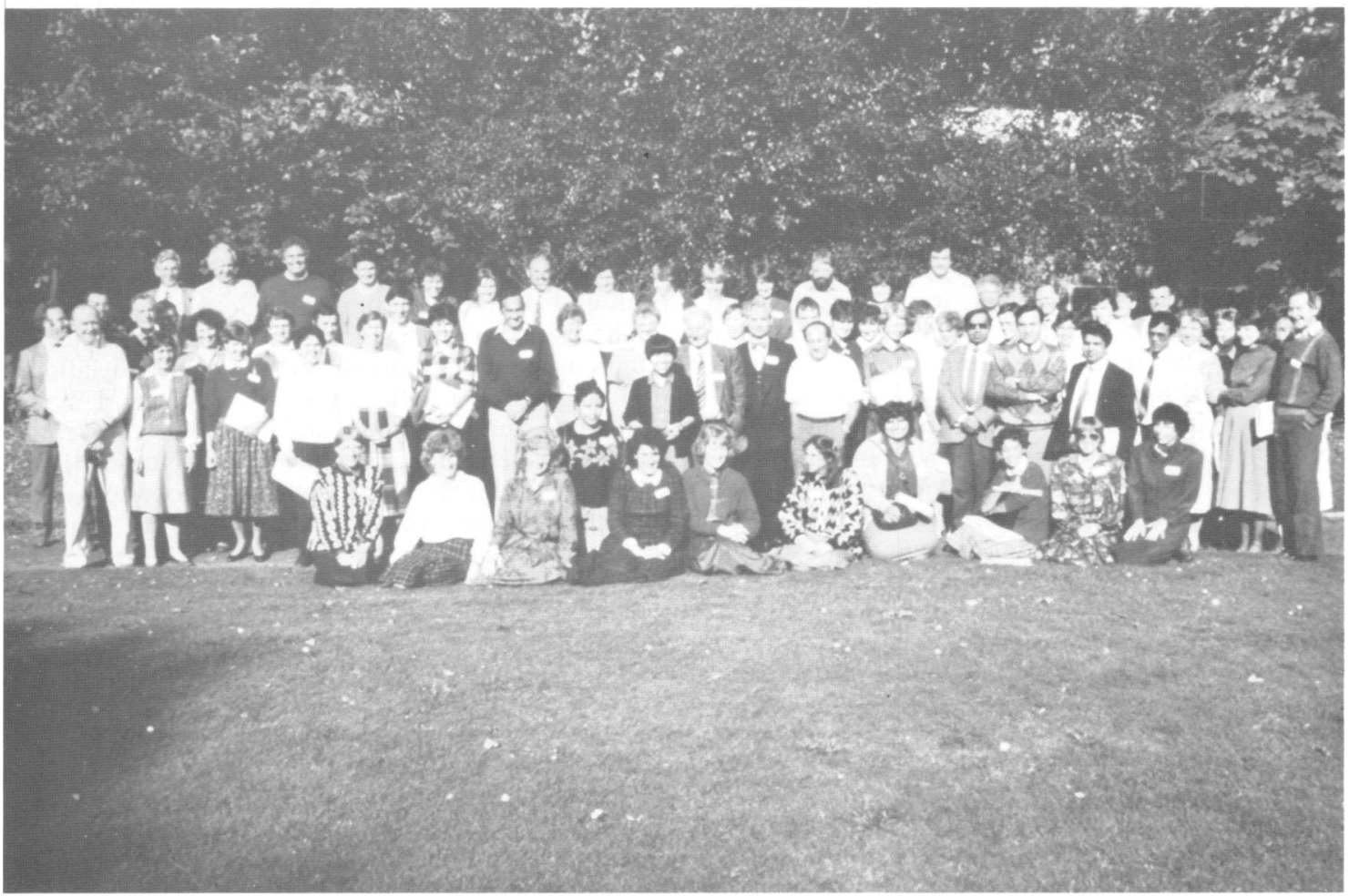


more than twice a lifetime's dose, while about 100 million suffered some degree of exposure. Various approaches to malformation monitoring were discussed including possible screening for new mutations in well documented genes, such as the haemophilia gene, factor VIII, and the collagen genes.

Moving from genes to embryology, Professor Mark W J Ferguson gave an inspired and inspiring presentation on his use of the alligator as an experimental model for the study of palate formation. He ranged from stealing eggs from irate lady alligators in the Louisiana swamps to laboratory experimental designs of intricate beauty: techniques to ablate the neural crest giving rise to a lower jaw so as to allow the palate to be watched closing in a partially opened egg, the use of hybrids of alligator embryos with quail cells to demonstrate cell migration patterns, and the use of specially designed culture beds to allow specific growth factors to be isolated. His explanation of sex determination in alligators and crocodiles excited a good deal of interest. It would seem that sex in these reptiles is determined by a small change in the incubation temperature of the egg; cooler and it's female, warmer male. Failure to realise this caused mayhem in Australia when crocodiles were protected from hunting. The first generation eggs hatched at the cool water's edge so the majority of offspring were female. This had the predictable explosive effect on population size.

John Aase from New Mexico gave a memorable discourse on the structure, normal and abnormal, of the external ear. He displayed the perception of his hero Sherlock Holmes in his analysis of the clinical significance of minor anomalies of pinna formation. He emphasised that the ear was rarely a good diagnostic handle though certain features were useful. Absence of the superior crus of the antihelix (check your anatomy textbook if necessary) is commonly accompanied by deafness, while compression in utero causes the ear to enlarge.

Robin Winter's database continues to go from strength to strength with over 1400 syndromes and 4500 references. Apart from providing an excellent means of gaining access to the syndrome literature, the computer programme is now beginning to provide a means of grouping together syndromes with a common pattern and matching up unknown syndromes from around this country and soon beyond.

Several syndromes were the subject of detailed analysis. Proteus syndrome, for example, was examined in detail by Robin Clark, now of California, and Denis Viljoen from Cape Town. The recent suggestion that the Elephant Man was afflicted by this overgrowth syndrome and not neurofibromato $\stackrel{9}{\Rightarrow}$ sis made these papers of particular interest. It woulds seem that this diagnostic label may threaten to engulf the Klippel-Trenaunay-Weber syndrome믈. Certainly, the boundary at present is somewhaff. blurred.

Authoritative reviews were given of several othen difficult syndromes, including Peter Farndon on the basal cell naevus syndrome, better referred to as Gorlin syndrome, Elizabeth Thompson on the $X$ linked FG syndrome, Cindy Curry on Neu-Laxova syndrome, Peter Beighton on the sclerosing bon dysplasias, Michael Baraitser on Rett an $\vec{\Phi}$ Angelman syndromes, Christine Oley on CHARGE association, and Mike Patton on Russell-Silve syndrome. New syndromes discussed included paper by Brian Hall on a recognisable pattern involving radial hypoplasia, thoracic and cervica hemivertebrae and less commonly clefting, faciat asymmetry, and renal defects. The occurrence i maternal half sibs of different sex raised the possibility of a single gene basis.

Roger Stephenson raised an interesting debate ono fetal encasement as a possible basis for syndromeș such as the Neu-Laxova syndrome. Another papeg from his team examined the abnormalities of arteria supply to the spinal column at the site of neural tube defects. The suggestion that the interrupted vasculad supply might be a primary cause did not convinces the sceptics who felt such anomalies were more likely to be chickens than eggs.

Abnormalities of the first and second branchia arches were a particular theme. Brian Hall reviewed Nager acrofacial dysostosis, P D Phelps examined. the ear and jaw deformities of hemifacial micros somia, and Peter Beighton presented a review ơ profound deafness in branchial arch syndromes.

The list is far from complete; from John Yates plumbing the murky depths of MURCS associatio to Ian Young's mystical paper on Mermaid ma尽 formation. Space is limited and immodesty prevent\$ me from overlooking my own contribution. The review of Williams syndrome needs no discussio since it was based on the syndrome of the month review in the October 1986 issue of the Journal. My one good unknown with polydactyly, renal agenesiso imperforate anus, and holoprosencephaly was imov mediately identified by Dr Donnai as the 'missin link' in her paper on the new syndrome which has io the past been called Pallister-Hall, severe Smith Lemli-Opitz, and Rutledge syndrome. My presenta? tion on branchial arch defects and the heart allowed me to explore the fascinating experimental embryo? ogy of Margaret Kirby and colleagues. Their abilit\$ to produce Di George syndrome by ablation of th cervical crest giving rise to the fourth branchial archo 
and the demonstration that single somite defects could impair septation of the outlet of the heart and produce perimembranous ventricular septal defects, fit together beautifully the clinical defects and the possible sites of gene action. She too used quail chimeras to demonstrate neural crest migration into the cardiac outlet, this time with chicken embryos rather than Mark Ferguson's aligators (quickens not qualigators). My one criticism was of the suggestion in one report that because absence of the spleen occurred with outlet defects of the heart, the neural crest might contribute to spleen formation. This is the old error of confusing association with cause. There is impressive evidence to show that absence of the spleen in the Ivemark syndrome results from a disturbance of laterality such that the body is isomeric with two right sides. My own preference is, therefore, for the term isomerism sequence but this debate highlights the danger of such terminology based on an interpretation of embryology. Are all cleft palates in babies with small jaws truly sequential as the Robin sequence would have us believe? We should, perhaps, heed cardiac anatomists and embryologists who have purged their terminology of such assumptions and restrict themselves to actual observations. Long live the straight forward eponymous syndrome.

I hope that most of the participants returned home with happy memories, particularly of the 'special item'. Together with Carol McKeown and Di Donnai I ended the unknown syndrome session with a test of the dysmorphologists' skills. They were shown pictures of themselves at a very early age to see if they could identify which furrowed face had evolved from which picture of innocence. It proved very entertaining since few of the victims realised that their spouses had betrayed them. Needless to say all copies of these slides have now been incinerated.

JOHN BURN

Department of Human Genetics, University of Newcastle upon Tyne, 19 Claremont Place, Newcastle upon Tyne $N E 24 A A$.

\section{Second International Workshop on Multiple Endocrine Neoplasia Type 2 (MEN 2), Cambridge, 17 to 20 September 1986}

MEN 2 is an autosomal dominant inherited cancer syndrome. It consists of medullary thyroid carcinoma (MTC), which arises from the calcitonin producing thyroid $\mathrm{C}$ cells, and phaeochromocytoma of the adrenal medulla. The five sessions of the Workshop reflected the diversity of scientific and clinical interest in this syndrome.

The first session dealt with radioimmunoassays and family screening. Both here and in a concluding round table, the consensus was that screening should be offered not only to members of known families, but to first degree relatives of patients with apparently sporadic MTC. The incomplete penetrance of the MEN 2 gene means that a negative family history may be misleading (Ponder, Sutton). Calcitonin remains the only satisfactory marker for screening for MTC; katacalcin values run parallel but offer no advantage, CGRP (calcitonin gene related peptide) seems not to be useful, and chromogranin A has yet to be fully evaluated. A review of European calcitonin assays (Gautvik,
Oslo) showed alarming variation in the results obtained with a standard panel of samples: most groups with experience in screening cross check their results in a second assay before advising thyroidectomy.

Genetic linkage studies have not so far produced a positive result. About $30 \%$ of the genome has been excluded (results collected by K Kidd (Yale) and N Simpson (Kingston)). More data was presented by the Detroit group in favour of the $20 \mathrm{p}$ - deletion, but this has not been seen by other laboratories, and a polymorphic DNA probe mapped by in situ hybridisation close to the supposed deleted band gives a strongly negative lod score. Flanking probes for the deletion have not, however, been identified.

Cell cultures derived from MTC have provided the opportunity to study the regulation of calcitonin (CT) gene expression, and of the differential splicing of the CT/CGRP precursor mRNA. Modulation of CT gene expression during growth of MTC cells in culture may reflect changes in the production of 